\title{
FORMAÇÃO DE PROFESSORES E ESTÁGIO SUPERVISIONADO: EXPERIÊNCIAS INTERDISCIPLINARES NA EDUCAÇÃO INFANTIL EM AULAS DE EDUCAÇÃO FÍSICA
}

\author{
Marília Del Ponte de Assis ${ }^{1}$ \\ Andrea Desiderio $^{2}$ \\ Carla Cristina Urbina Carrion ${ }^{3}$ \\ Leonardo Rodrigo Borges ${ }^{4}$ \\ Camila da Silva Oliveira ${ }^{5}$ \\ Eliana Ayoub ${ }^{6}$
}

\section{Introdução}

Na Faculdade de Educação da Unicamp, o desenvolvimento das atividades organizadas na disciplina Estágio Supervisionado (EL874) prevê a imersão no campo de trabalho de tal forma que seja propiciado aos estudantes em formação, futuros professores e professoras, o contato com experiências, práticas e conhecimentos de natureza profissional.

Além de se aproximar do trabalho desenvolvido na instituição escolar, onde deverão conhecer as características que envolvem a ação profissional, os estudantes devem pensar, planejar e elaborar uma proposta de ação com os professores da escola em que se inserem, numa dimensão coletiva e interdisciplinar (AYOUB; PRADO, 2013). Isso implica na elaboração de atividades que possam ser desenvolvidas tanto em sala de aula, nas diferentes disciplinas curriculares, quanto em outros espaços educativos dentro do campo de estágio. A cada aula da disciplina na universidade, propõe-se uma reflexão coletiva sobre as diversas experiências de estágio.

O presente texto é uma versão ampliada do trabalho intitulado "Uma lenda africana" e tem como objetivo compartilhar as propostas realizadas na Escola do Sítio (em Campinas/SP) no contexto da disciplina de estágio supervisionado, sob responsabilidade da Profa. Dra. Eliana Ayoub, com apoio da doutoranda Marília Del Ponte de Assis, participante do Programa de Estágio Docente (PED/Unicamp). Para tal, apresentamos as bases do trabalho da supervisora de estágio, Andrea Desiderio, que atua como professora de educação física na educação infantil (com crianças entre 1 ano e meio e 5 anos de idade), bem como as experiências, ações e reflexões dos estagiários Carla Carrion (Licenciatura em Educação Física), Leonardo Borges (Licenciatura em Química) e Camila Oliveira (Licenciatura em Ciências Biológicas)

\section{A Escola do Sítio e as aulas de educação física}

Fundada em 1976, a Escola do Sítio é uma instituição privada de ensino, localizada no distrito de Barão Geraldo, na cidade de Campinas/SP. Seu nome faz alusão ao sítio de 6.000 $\mathrm{m}^{2}$, com grande área de jardins, pomar, horta, tanques de areia, borboletário e quadras que

\footnotetext{
${ }^{1}$ Universidade Estadual de Campinas.

${ }^{2}$ Universidade Estadual de Campinas.

${ }^{3}$ Universidade Estadual de Campinas.

${ }^{4}$ Universidade Estadual de Campinas.

${ }^{5}$ Universidade Estadual de Campinas.

${ }^{6}$ Universidade Estadual de Campinas.

${ }^{7}$ Apresentado no "I Seminário Experiências em Estágio Docente, VI Encontro e II Mostra do PIBID-Unicamp e XII Encontro de Estudantes de Graduação dos Cursos de Formação de Professores da Unicamp”, realizado na Faculdade de Educação da Unicamp, dias 26 e 27/11/2015.
} 
compõem seu campus. Ao optar por um currículo aberto, que prioriza a participação efetiva de seus alunos nas situações de aprendizagem, a Escola do Sítio tornou-se uma referência de instituição ao buscar a formação de crianças e jovens autônomos, atuantes e que saibam conviver com a diversidade. Abrangendo desde o maternal até o ensino fundamental I e II, as turmas têm em média vinte alunos que convivem em um espaço coletivo. Isso permite um olhar individualizado para as capacidades e necessidades de cada aluno, inclusive para aqueles com necessidades especiais, o que enriquece o contexto educativo ${ }^{8}$.

O espaço da Escola do Sítio é bastante propício para o desenvolvimento de diferentes linguagens, dentre elas a corporal. Tal contexto possibilita diversificados encontros, e no espaço onde o encontro acontece, o humano se transforma (BARBUY, 1980).

Nas aulas de educação física na educação infantil, o brincar é valorizado como algo que vai muito além do desenvolvimento de habilidades corporais (AYOUB, 2001 e 2005). Assim como outras formas culturais construídas historicamente no plano material e simbólico, o brincar também possui valor cultural, social e humano neste contexto. Nesse sentido, as bases teóricas que fundamentam o trabalho da educação física na escola partem principalmente da interlocução com as ciências humanas e sociais. Essa escolha possibilita conhecer práticas corporais pelo olhar da história, da sociologia, da filosofia, da antropologia e da arte, tornando o fazer corporal um possível campo para a experiência de cada um dos alunos e professores (SILVA; DAMIANI, 2005; LARROSA, 2014). Ademais, considera-se a experiência como "[...] um convite para romper com os sistemas de educação que dão o mundo já interpretado, já configurado de uma determinada maneira, já lido e, portanto, ilegível" (LARROSA, 2015, p. 11).

Bastante procurada para fins de estágio, esta escola preocupa-se em não apenas receber novas pessoas, mas também abrir-se para o outro, para o novo, para aqueles que estão em busca da tão almejada "formação". Com isso, as crianças já estão acostumadas à presença de estudantes universitários no seu dia-a-dia, e as aulas de educação física seguem este pensamento, tendo recebido anualmente cerca de dois ou três estagiários. A própria professora desta disciplina foi estagiária na Escola do Sítio em 2002, e desde 2005 continua esta parceria entre a escola e a universidade.

Conforme explicitamos anteriormente, no segundo semestre de 2015, três estudantes da Unicamp procuraram a instituição para realização do estágio, com formações diversas: uma estudante de educação física, uma de biologia e um de química, com o desafio de fazer o estágio em grupo, numa perspectiva interdisciplinar. Houve uma curiosidade e apreensão inicial da supervisora ao acompanhar estagiários vindos de áreas tão distintas, mas a abertura de todos para a criação de possibilidades de encontro foi fundamental para que, juntos, encontrassem caminhos possíveis de interlocução. Com o caminhar dos encontros e conversas, durante e após as aulas, decidiu-se por abordar temas sobre ginástica e circo com as turmas acompanhadas. $\mathrm{O}$ trio de estagiários atuou diretamente com as turmas, sempre sob supervisão da Andrea, e uma das propostas desenvolvidas foi tematizar práticas corporais gímnicas durante a Festa Africana, e tematizar o circo com espaço para atividades de truques de mágica e mistérios da química.

\section{Festa africana e as práticas corporais gímnicas}

Para tematizar a ginástica e demais práticas corporais, a proposta de ação dos estagiários baseou-se na realização de uma Festa Africana, motivada por uma lenda que relata o surgimento do tambor. A lenda foi adaptada, com a intenção de incluir aspectos que seriam necessários para o trabalho com as crianças, objetivando mostrar parte da cultura africana por meio da

\footnotetext{
${ }^{8}$ Para conhecer maiores detalhes sobre a escola, consultar <http://www.escoladositio.com.br/ $>$.
} 
ludicidade da lenda e da musicalidade. O grupo de estagiários iniciava a aula narrando a lenda para os alunos, estimulando sempre a participação das crianças, por meio de perguntas interativas. Segue abaixo um resumo da lenda adaptada:

Um bando de macaquinhos vivia em uma floresta da África. Eles, que eram muito curiosos e espertos, eram protegidos por corajosos guerreiros $e$ corajosas guerreiras, que usavam grandes máscaras para lhes dar coragem. Um dia, um dos macaquinhos teve a ideia de tocar a Lua. Como os outros macaquinhos acharam que a ideia era muito boa, eles decidiram subir um em cima do outro até alcançar a grande luz brilhante no céu. Porém, os macaquinhos que estavam na parte de baixo da grande escada de macacos, começaram a ficar cansados e, assim, eles acabaram caindo no chão, deixando apenas um macaquinho preso na Lua. A Lua, vendo a aflição do macaquinho em querer voltar pra Terra, decide ajudá-lo. Para isso, ela entregou a ele uma corda e um tambor, dizendo que era para ele tocar o instrumento quando chegasse ao solo, pois assim ela poderia cortar a corda. Entretanto, o macaquinho que era muito curioso decidiu, durante a descida, tocar o tambor para descobrir o som que fazia. A Lua, pensando que o bichinho havia chegado ao solo, cortou a corda. O macaquinho veio ao chão e durante a queda o tambor se perdeu na selva. Com o intuito de achar o instrumento, os macaquinhos pediram ajuda aos guerreiros e às guerreiras. Depois de muito procurar, todos acabaram encontrando o tambor e uma grande festa foi realizada para comemorar. Cada vez que os macaquinhos tocavam o tambor, a Lua brilhava mais intensa no céu.

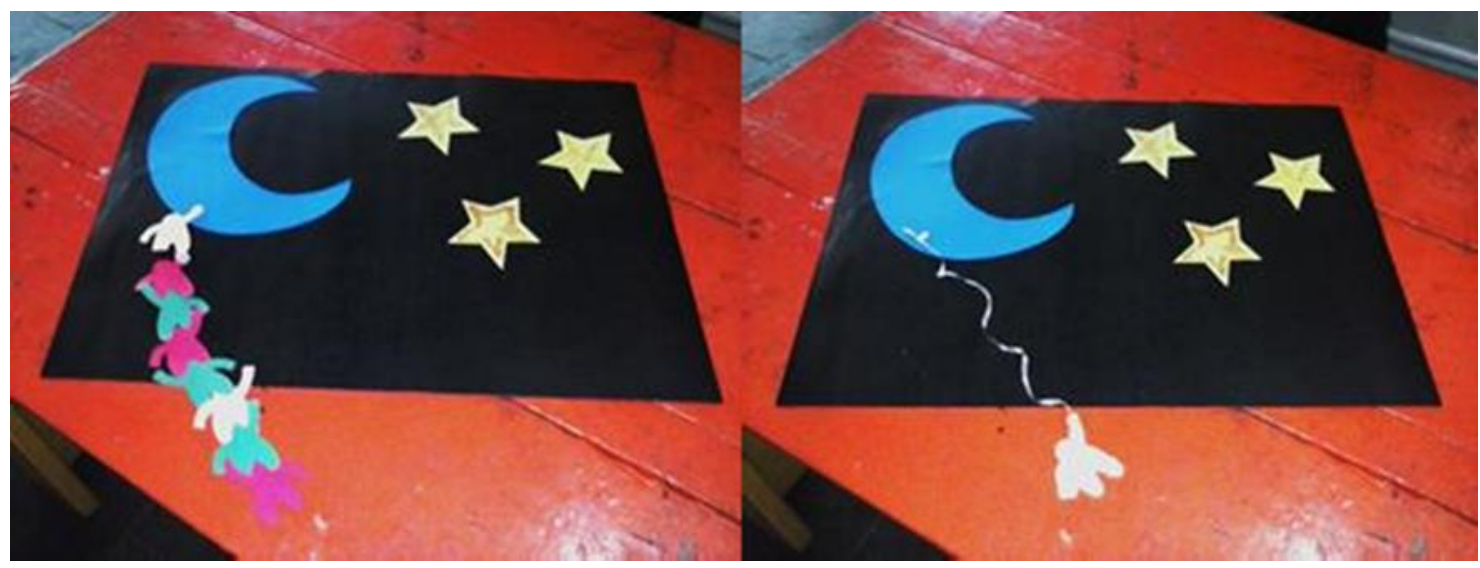

Figura 1: Macaquinhos subindo na Lua e depois o macaquinho descendo com o tambor e o fio que a Lua deu para ele.

Os estagiários confeccionaram máscaras africanas para que os alunos se sentissem como os grandes guerreiros e guerreiras da história. As crianças foram, então, convidadas a participar de um circuito montado com aparelhos de ginástica e móveis da escola, na busca do tambor perdido (um tambor estava escondido próximo ao local da aula). Os alunos atravessaram "pontes perigosas" (bancos e tábuas de madeira), passaram por "cavernas escuras" (mesa de madeira encoberta por panos), mergulharam em "lagos perigosos" (panos azuis sobre colchões) e "pularam rios cheios de jacarés" (fio de barbante estendido no chão). 


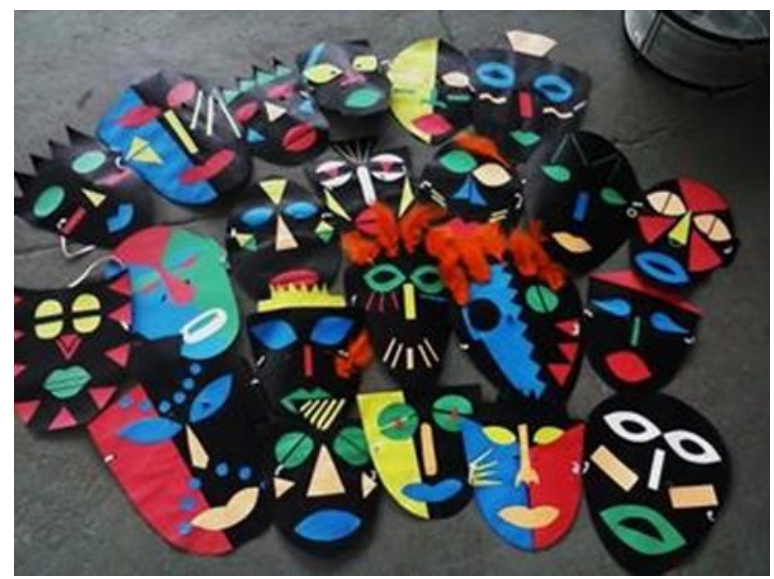

Figura 2: Máscaras dos guerreiros africanos confeccionadas pelos estagiários.
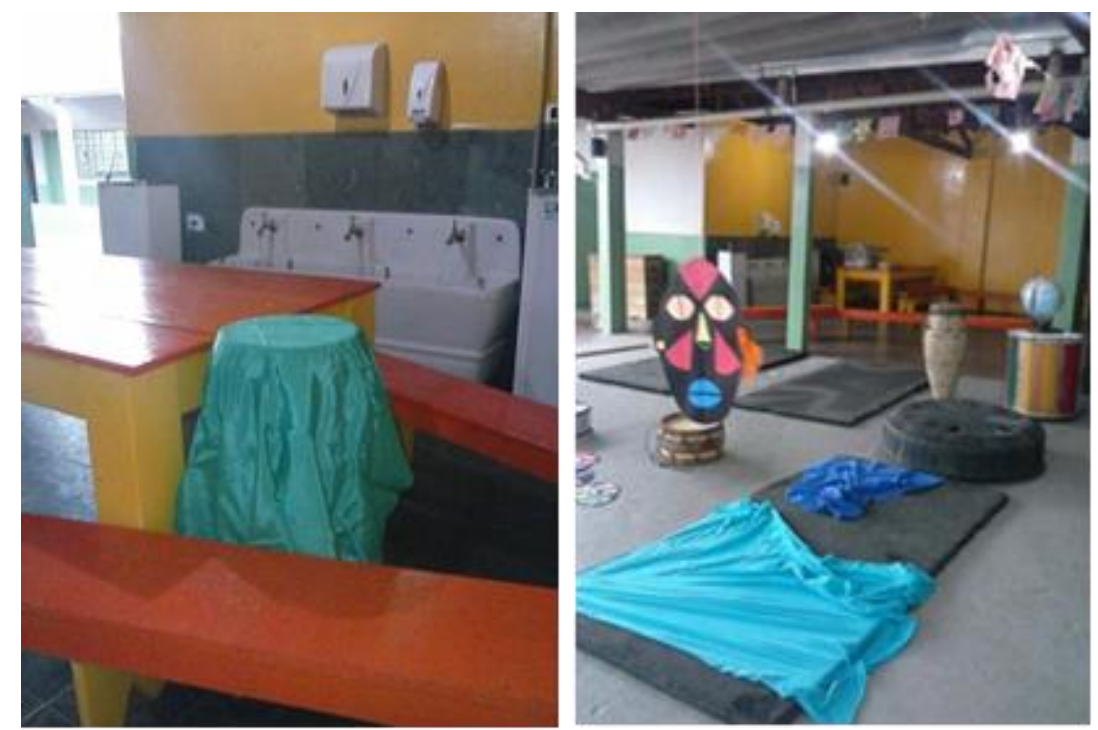

Figuras 3 e 4: O tambor e cenário para encontrar o tambor.

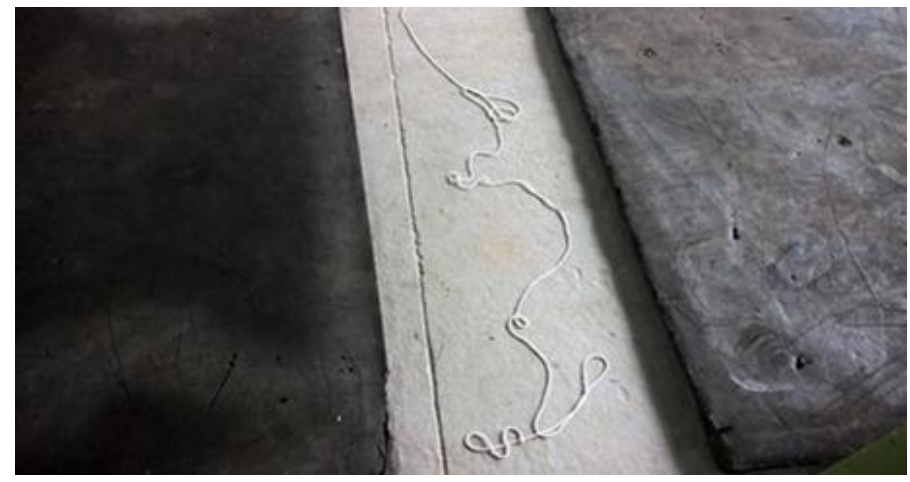

Figura 5: "Rio sinuoso cheio de jacarés".

Após encontrarem o tambor, os alunos ficavam livres para dançar e se divertir ao som de uma música tipicamente africana. Como finalização da atividade, uma folha sulfite com uma máscara africana impressa em preto e branco foi entregue a cada aluno, para que pudessem colorir à sua própria maneira. $\mathrm{O}$ envolvimento das crianças com as atividades propostas foi visível tanto no processo de organização quanto durante a realização da festa. A interação com 
o cenário, pensado segundo a lenda africana, serviu de estímulo para diversas explorações e criações.

\section{Truques de mágica e os mistérios da química}

A presença de estudantes de cursos de formação de professores nas áreas de química e biologia na educação infantil proporcionaram novas reflexões sobre a prática pedagógica. Os "mistérios das ciências" podem ser apresentados desde cedo aos alunos, e a experiência na Escola do Sítio mostra que numa aula da disciplina de educação física, neste caso tematizando o circo, a química pôde ser demonstrada, iniciando uma familiaridade dos alunos com o tema da matéria e suas transformações, que são a base da ciência química.

A partir da temática do circo, proposta pela professora para um conjunto de aulas, as crianças tiveram contato com experimentos químicos simples ${ }^{9}$, que puderam ser visualizados sob a ótica de truques de mágica. Foram demonstradas reações que contaram com estímulos visuais (coloração de líquidos, mudança de cor de líquidos) obtidos a partir do uso de materiais como corantes alimentícios, vela, sabão, limão, vinagre, giz, bicarbonato de sódio, repolho roxo. Para crianças um pouco maiores que observaram a aula, uma breve explicação dos fenômenos ocorridos foi realizada e muitos alunos chegaram até mesmo a formular suas próprias hipóteses, o que é fundamental para o desenvolvimento e a existência da ciência.

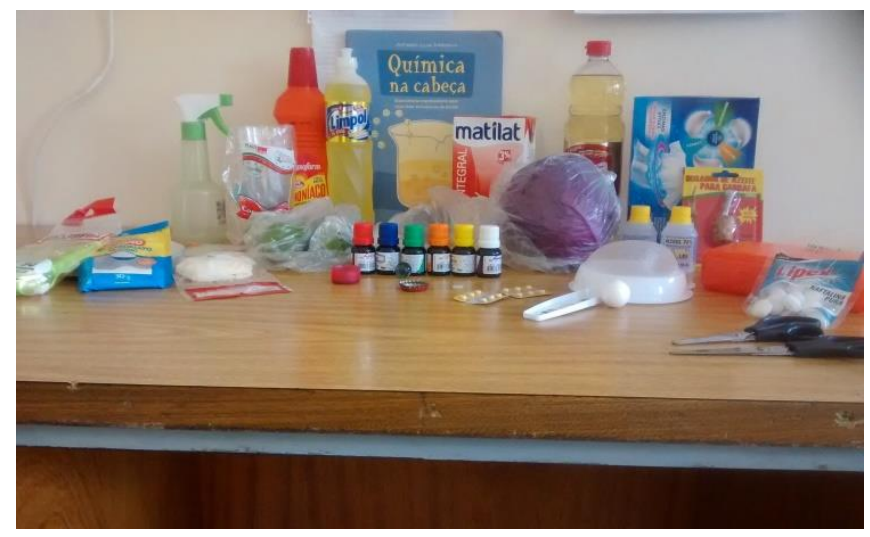

Figura 6: Materiais para as mágicas.

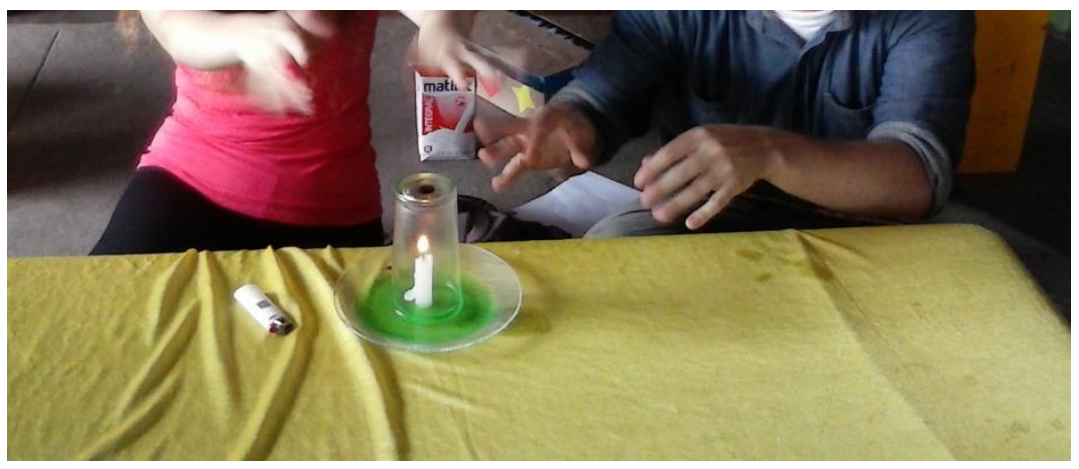

Figura 7: Estagiários fazendo mágicas.

O contexto de desenvolvimento do estágio foi muito propício à realização dessa atividade: a própria proposta pedagógica da Escola do Sítio, que favorece espaço para o novo e a criação

\footnotetext{
${ }^{9}$ Os experimentos foram retirados do livro "Química na cabeça: experiências espetaculares para você fazer em casa ou na escola", de Alfredo Luis Mateus (2001).
} 
conjunta entre alunos e professores; a abertura do estágio para a educação infantil, mesmo em se tratando de áreas tão diversificadas como educação física, química e biologia e o desafio de criar propostas interdisciplinares; o fortalecimento da ideia, ao longo do estágio, de que os alunos são capazes de produzir conhecimento e que cabe a nós, professores, respeitar o tempo de cada aluno, sua lógica de pensamento, auxiliando-os nesse processo.

\section{Considerações finais}

A partir das experiências de estágio na Escola do Sítio, onde o tempo, o desenvolvimento, os limites, as possibilidades e os interesses de cada aluno são considerados, pudemos refletir sobre a importância de se respeitar as diferentes formas de conhecimento e de saberes do ser humano.

Em diversas situações, fomos desafiados a interagir com as crianças de forma aberta, lúdica, observando minuciosamente seus modos de agir, de conhecer, de criar, de transformar, de ousar. Nesse caminho de aprendizados mútuos, compreendemos a profundidade do ensinamento de Georges Snyders (1988, p. 218), quando afirma: "Não considere seus alunos tolos". Ensinamento que atravessou nossas ricas experiências de estágio e que trouxe aprendizados significativos para a formação docente.

\section{Referências}

AYOUB, E. Reflexões sobre a educação física na educação infantil. Revista Paulista de Educação Física, São Paulo, supl. 4, p. 53-60, 2001.

Narrando experiências com a educação física na educação infantil. Revista Brasileira de Ciências do Esporte, Campinas, v. 26, n. 3, p. 143-158, 2005.

AYOUB, E.; PRADO, G. V. T. Abordagens interdisciplinares nos estágios curriculares na formação de professores.Olh@res, Guarulhos, SP, v. 1, n. 1, p. 378-400, maio/2013.

BARBUY, S. O espaço do encontro humano. São Paulo: ECE Editora, 1980.

LARROSA, J. Tremores: escritos sobre experiência. Belo Horizonte: Autêntica, 2014.

Pedagogia profana: danças, piruetas e mascaradas. $5^{\text {a }}$ edição. Belo Horizonte: Autêntica, 2015.

MATEUS, A. L. Química na cabeça: experiências espetaculares para você fazer em casa ou na escola. Belo Horizonte: Editora UFMG, 2001.

SILVA, A. M. ; DAMIANI, I. R. As práticas corporais e seu processo de res-significação. In: . (Org.). Práticas Corporais Volume 1: gênese de um movimento investigativo em Educação Física. Florianópolis: Nauemblu Ciência e Arte, 2005.

SNYDERS, G. A alegria na escola. São Paulo: Manole, 1988. 


\section{Sobre os autores}

Marília Del Ponte de Assis é graduada em Educação Física (Puccamp) e mestra em Educação Física (UFSC), atualmente é doutoranda em Educação pela Unicamp (Linha de Pesquisa Formação de Professores e Trabalho Docente) e membro do Laboratório de Estudos sobre Arte, Corpo e Educação (Laborarte).

E-mail: mdpassis@yahoo.com.br.

Andrea Desiderio é graduada e mestra em Educação Física pela Unicamp, é também membro do Grupo de Pesquisa em Ginástica da Faculdade de Educação Física da Unicamp. Artista, acrobata, pesquisadora da infância e das práticas corporais, é professora de Educação Física na Escola do Sítio desde 2005.

E-mail: andreaggu@yahoo.com.br.

Carla Cristina Urbina Carrion é bacharel e licenciada em Educação Física pela Unicamp. E-mail: carlinhacarrion@gmail.com.

Leonardo Borges é estudante do curso de Química na Unicamp. Bolsista PIBID no subprojeto de licenciatura em Química.

E-mail: leonardorodrigoborges@gmail.com.

Camila da Silva Oliveira é licenciada e bacharel em Ciências Biológicas pela Unicamp, atua na área de Taxonomia e Sistemática de Angiospermas.

E-mail: camilasoliveira93@gmail.com.

Eliana Ayoub é docente da Faculdade de Educação da Unicamp. Membro do Laboratório de Estudos sobre Arte, Corpo e Educação (Laborarte) e do Grupo de Pesquisa em Ginástica da Faculdade de Educação Física da Unicamp.

E-mail: ayoub@unicamp.br. 